\title{
Individuell variasjon i utskillelse av 6-sulfatoksymelatonin og døgnrytmetype analysert hos skiftarbeidere
}

\author{
Tore Tynes ${ }^{1}$, Bjarte Haugsdal ${ }^{1}$, Arnfinn Tønnessen ${ }^{1}$ og Magnar Kleiven ${ }^{2}$ \\ 1. Statens strålevern, 1332 Østerås \\ 2. Norsk Hydro, 3903 Porsgrunn \\ Korrespondanse: Tore Tynes, Statens strålevern, postboks 55, 1332 Østerås \\ e-post: tore.tynes@nrpa.no
}

\begin{abstract}
SAMMENDRAG
I denne studien har vi undersøkt om det finnes noen sammenheng mellom målte verdier av urinmetabolitten 6-sulfatoxymelatonin (aMT6s) tatt ut i porsjoner gjennom døgnet og selvrapportert døgnrytme hos en gruppe norske skiftarbeidere. Studien omfatter 19 arbeidstakere ved to produksjonsenheter ved Hydro Porsgrunn, magnesiumfabrikken og fullgjødselfabrikk 3. Etter å ha deltatt i en studie der urinprøver ble samlet inn, svarte de involverte senere på et spørreskjema om søvn og døgnrytme. Resultatene indikerer at egenrapporterte B-type mennesker har en tendens til høyere midlere timeutskillelse av aMT6s analysert på døgnbasis første døgn med nattskift, og en signifikant høyere nattutskillelse (8 timer) i et kontrolldøgn hjemme. I fremtidige studier av melatoninsekresjon og utskillelse av metabolitt i urin, kan det være av interesse samtidig å samle inn spørreskjemabaserte opplysninger om døgnrytmetype og utfyllende opplysninger om søvn og søvnmønster i relasjon til eksponeringer som skiftarbeid og andre arbeidsmiljøfaktorer som kan ha effekt på hormonbalansen.
\end{abstract}

\section{Tynes T, Haugsdal B, Tønnessen A, Kleiven M. Individual variations in excretion of 6-sulfatoxymelatonin in morning and evening type Norwegian shift workers. Nor J Epidemiol 1999; 9 (1): 33-38.}

\section{ENGLISH SUMMARY}

The aim of this study was to evaluate whether there is an association between measured values of the urine metabolite 6-sulfatoxymelatonin (aMT6s) in samples collected at selected intervals and self-reported diurnal rhythm in a group of Norwegian shift workers. The study included 19 workers at two production units at Hydro Porsgrunn, the magnesium factory and fertiliser factory 3. After submitting the urine samples used for the study, subjects filled in a questionnaire on sleep and diurnal rhythm at a later date. The results indicate that self-reported evening type subjects have a tendency towards a higher mean hourly aMT6ssecretion first day on night shift, and a significantly higher night secretion ( 8 hours) analysed for a control day at home. In future studies on secretion of melatonin and its metabolite in urine, the collection of questionnaire-based information on diurnal type, sleep and sleep pattern in relation to exposures like shift work, and other work-related factors with potential effect on hormone balance might be of interest.

\section{INNLEDNING}

Den humane biologiske klokke eller den "circadiane" rytme har som en oppgave å forberede kroppen og hjernen for hvilegivende søvn en del av døgnet og aktiv våkenhet $\mathrm{i}$ en annen del av døgnet. Hos eldre kan denne klokken komme ut av rytme og gi søvnløshet (1). I 1958 isolerte Lerner melatonin, et hormon som utgjør hovedsubstansen syntetisert i epifysen (2). Man har nå holdepunkt for at melatonin kan ha en rolle $\mathrm{i}$ den biologiske reguleringen av døgnrytmer, søvn, stemningsleie, og kanskje reproduksjon, aldring og sykdomsutvikling (1). Hos mennesket er døgnrytmen for frigivelse av melatonin nært synkronisert med søvnmønsteret. Søvnforstyrrelser etter reise gjennom tidssoner og ved tilstander av absolutt blindhet er assosiert med forstyrrelser i denne rytmen. Hos eldre med innsovningsvansker er melatoninkonsentrasjonen vist å være signifikant lavere og med toppverdi senere på natten enn hos eldre uten søvnforstyrrelser (3). Lys og inntak av melatonin kan endre den normale døgnrytmen av melatoninsekresjonen (4), men de rapporterte funn er ikke konsistente, og kan være forårsaket av at lysbehandlingen og inntak av melatonin er foretatt på ulike tidspunkt i syklusen.

Etter at Kleitmann i 1939 beskrev "morning-type (M) and evening type (E)" mennesker, på norsk A- og B-mennesker (A- og B-type) (5), har ulike aspekter av 
dette vært belyst i relasjon til selvrapportert døgnrytme. Flere svenske studier har bidratt til vår kunnskap om skiftarbeid og selvrapportert døgnrytme $(6,7)$.

Når døgnrytmen generelt hos eldre sammenlignes med yngre mennesker, ser det ut til at eldre oftere vil være av A-type og våkne tidligere enn yngre mennesker (8). Ifølge Kerkhof er morgen/kveldstypekarakteren den viktigste faktor assosiert med pålitelige interindividuelle forskjeller i døgnrytme (9).

Sammenhengen mellom A- og B-typer og melatoninsekresjon er tidligere undersøkt $\mathrm{i}$ en studie blant 20 friske menn og kvinner som fikk målt nattutskillelse av melatonin i urinen. Studien viste ingen signifikant forskjell mellom A- og B-typer (10).

Som ledd i et større biorytmeprosjekt hadde vi anledning til å sammenholde målte verdier av urinmetabolitten aMT6s tatt ut i porsjoner gjennom døgnet med en senere gjennomført spørreskjemaundersøkelse hvor blant annet forhold omkring søvn og døgnrytme inngikk. Vi valgte ut de svarene i spørreskjemaet som vi antok kunne være av betydning for studiedeltagernes melatonin-nivåer, for om mulig å trekke konklusjoner vedrørende en eventuell anvendelse av denne type spørreskjema i fremtidige studier. Biorytmeprosjektet var i utgangspunktet laget for å se på eventuelle effekter på aMT6-utskillelsen hos grupper av skiftarbeidere med og uten eksponering for magnetfelt. Funnet som rapporteres her er således et bifunn i studien.

\section{MATERIALE OG METODE}

\section{Deltagere}

Studien omfatter 19 arbeidstakere ved to produksjonsenheter ved Hydro Porsgrunn, magnesiumfabrikken og fullgjødselfabrikk 3. Et spørreskjema, inkludert et informasjonsskriv, ble sendt til disse skiftarbeiderne som alle hadde deltatt i det tidligere biorytmeprosjektet (12). Prosjektet omfattet innsamling av urinprøver, som på magnesiumfabrikken ble gjennomført i perioden november 1996 til februar 1997 og på gjødselfabrikken i perioden november-desember 1997. Spørreskjemaundersøkelsen ble gjennomført i april 1998 og var basert på frivillighet. Etter svarfristens utløpt og én purrerunde hadde 19 personer $(73 \%)$ besvart skjemaet. Det er altså inntil 1,5 års intervall mellom tidspunkt for prøvetaking og innsamling av spørreskjema. Deskriptive variable for personene som inngår i analysen er gitt i tabell 1. I tillegg bør nevnes at målt midlere døgn- og nattnivå av aMT6s ved magnesiumfabrikken var 0,92 og $1,73 \mu \mathrm{g} / \mathrm{t}$ og ved fullgjødselfabrikken 0,72 og 1,49 $\mu \mathrm{g} / \mathrm{t}$. Fordeling av A- og B-typer var lik på de to arbeidssteder. Midlere alder var lavere ved fullgjødselfabrikken (35 år mot 48 år).

\section{Sporreskjema}

Skjemaet som ble benyttet, var en norsk oversettelse av "Survey of Shiftworkers," som er en forkortet versjon av "Standard Shiftwork Index" (11). Følgende spørsmål fra spørreskjemaet er tatt med i analysen: (i) hvor lenge har du totalt jobbet skift?, (ii) er du den typen person som føler deg best tidlig på morgenen og føler deg trettere enn folk flest om kvelden?, (iii) er du den typen person som synes det er lett å sove til uvanlige tider på ukjente steder? For (ii) og (iii) basert på avkryssing på en skala fra 1 (absolutt ikke) til 9 (absolutt).

På grunn av det lave antall deltakere og dermed få besvarelser innen hver kategori, 1-9, ble det for variablene (ii) og (iii) $i$ en videre analyse foretatt en deling av materialet $\mathrm{i}$ tre grupper; for (ii), $(1 ; 2 ; 3)=\mathrm{A}$-type, $(4 ; 5 ; 6)=$ Intermediær (I)-type, $(7 ; 8 ; 9)=$ B-type. Dette er i overenstemmelse med tidligere anbefalt klassifisering av døgnrytmetyper (7). For variabel (iii) ble det benyttet $(1 ; 2 ; 3)=1,(4 ; 5 ; 6)=2,(7 ; 8 ; 9)=3$. Denne nye inndelingen innebærer at de som faller i gruppe 1 og 3 uttrykker egenskaper som tenderer mot henholdsvis "absolutt ikke" og "absolutt". Gruppe 2 representerer det nøytrale (verken/eller) mellomsjiktet.

Tabell 1. Beskrivelse av personer som inngår i analysen av spørreskjema og målte verdier av 6-sulfatoksymelatonin i urin.

\begin{tabular}{|c|c|c|c|}
\hline Variabel & kategori & Beskrivelse & antall \\
\hline \multicolumn{4}{|l|}{ Alder } \\
\hline & 1 & $<30$ år & 4 \\
\hline & 2 & 30-39 år & 5 \\
\hline & 3 & $40-49$ år & 9 \\
\hline & 4 & $\geq 50$ år & 6 \\
\hline \multicolumn{4}{|c|}{ Arbeidssted } \\
\hline & 1 & Magnesiumfabrikk, kontrollrom & 10 \\
\hline & 2 & Gjødselfabrikken & 14 \\
\hline \multicolumn{4}{|c|}{$\begin{array}{l}\text { Svart på } \\
\text { spørreskjema }\end{array}$} \\
\hline & 1 & $\mathrm{Ja}$ & 19 \\
\hline & 2 & $\mathrm{Nei}$ & 5 \\
\hline \multicolumn{4}{|c|}{$\begin{array}{l}\text { Antall år } \\
\text { i skiftarbeid }\end{array}$} \\
\hline & 1 & $<5$ år & 1 \\
\hline & 2 & 5-9 år & 1 \\
\hline & 3 & $10-14$ år & 4 \\
\hline & 4 & 15-19 år & 3 \\
\hline & 5 & $\geq 20$ år & 10 \\
\hline \multicolumn{4}{|c|}{$\begin{array}{l}\text { Opplysning } \\
\text { om søvn }\end{array}$} \\
\hline & 1 & absolutt ikke lett for å sove & 3 \\
\hline & 2 & & 1 \\
\hline & 3 & Sannsynligvis ikke lett for å sove & 1 \\
\hline & 4 & & 0 \\
\hline & 5 & Midt imellom & 3 \\
\hline & 6 & & 2 \\
\hline & 7 & Sannsynligvis lett for å sove & 6 \\
\hline & 8 & & 2 \\
\hline & 9 & Absolutt lett for å sove & 1 \\
\hline \multicolumn{4}{|c|}{ Mennesketype } \\
\hline & 1 & Absolutt B-menneske & 2 \\
\hline & 2 & & 1 \\
\hline & 3 & Sannsynligvis B-menneske & 2 \\
\hline & 4 & & 1 \\
\hline & 5 & Midt imellom & 7 \\
\hline & 6 & & 1 \\
\hline & 7 & Sannsynligvis A-menneske & 4 \\
\hline & 8 & & 1 \\
\hline & 9 & Absolutt A-menneske & 0 \\
\hline
\end{tabular}


Fra biorytmeprosjektet ble følgende data benyttet; (i) alder, (ii) arbeidsplass, magnesiumfabrikkens elektrolysehall/kontrollrom og gjødselfabrikken, (iii) midlere mengde aMT6s ( $\mu \mathrm{g} /$ time) fra kveld- og nattintervall i hjemmedøgn, (iv) midlere mengde aMT6s ( $\mu \mathrm{g} /$ time) første skiftdøgn.

Ettersom deltakerne ved magnesiumfabrikken har to sett analyseverdier, henholdsvis tilknyttet skiftperioden i elektrolysehallen og i kontrollrommet, har vi i denne studien valgt å benytte datasettet fra kontrollrommet, det mest komplette datasettet. Da målte verdier av døgnutskilt aMT6s hjemme i vårt materiale antas å ikke være pålitelige, er det $\mathrm{i}$ analysene benyttet midlere timeutskillelse første døgn på skiftarbeid. Dette døgnet antar vi er minst påvirket av eksponeringer knyttet til skiftet eller eksponeringer på jobb.

\section{Urinanalyser}

Hver deltaker ble tildelt prøvetakingsutstyr bestående av to stk. $1000 \mathrm{ml}$ volumgraderte samleflasker for urin samt 17 sett á 2 stk. prøveflasker $(20 \mathrm{ml})$, merket med analysekode, dato og klokkeslett for prøvetaking. Hvert døgn i studieperioden ble inndelt i fire prøvetakingsintervall, natt ( 8 timer), morgen (4 timer), dag ( 8 timer) og kveld (4 timer). Innen hvert intervall ble urin samlet og prøver ble tatt fra samleflaske ved slutten av hvert intervall. Avlest volum og evt. avvik fra tidsskjema ble rapportert på et prøvetakingsskjema. Med noen unntak ble prøvetakingen holdt akseptabelt ( \pm 0,5 time) innenfor skjematidene. Deltakerne leverte sine prøver hos bedriftshelsetjenesten, hvor de ble samlet og videresent porsjonsvis til fryselager og holdt ved $-50{ }^{\circ} \mathrm{C}$ inntil analyse. Urinprøvene ble sendt $\mathrm{i}$ frosset tilstand (pakket i tørris) til Stockgrand Ltd., Guildford, England, for analyse. Det ble benyttet en radioimmunoassay (RIA) metode for bestemmelse av aMT6s.

\section{Statistiske analyser}

Assosiasjonen mellom de ulike variable ble undersøkt ved å beregne gammakoeffisient for de bivariate korrelasjoner. Siden materialet er lite, og vi ikke antar intervallegenskaper ved variabler knyttet til A og B-type, har vi i analysen valgt å presentere bivariat korrelasjon mellom ulike modelleringsvariable og utskillelsen av aMT6 gitt ved Spearmans rank korrelasjonskoeffisient. Pearsons korrelasjonskoeffisient som forutsetter normalfordelte data og intervallegenskaper ved variabler, ga tilsvarende resultater. Vi har derfor beregnet partiell korrelasjonskoeffisient med kontroll for potensielle confoundere (arbeidssted og alder), basert på en matrise av Pearsons produkt-moment (nullte orden). Analysen ble foretatt i statistikkpakken SSPS (13).

\section{RESULTATER}

Midlere timeproduksjon av aMT6 første døgn på jobb blant 19 arbeidstakere henholdsvis i magnesium- fabrikkens kontrollrom og i gjødselfabrikken var 0,876 $\mu \mathrm{g} / \mathrm{l}$ (standard feil, SE $\pm 0,084$ ). Gjennomsnittlig produksjon for 8 timers kontrollnatt hjemme var 1,669 $\mu \mathrm{g} / \mathrm{l}(\mathrm{SE} \pm 0,177)$. Tabell 2 viser gammakoeffisienten for assosiasjonen mellom de ulike faktorer brukt $i$ analysen. Alder og tid i skiftarbeid er høyt korrelert. Det samme gjelder arbeidssted og henholdsvis alder og tid i skiftarbeid. De ansatte i gjødselfabrikken var gjennomgående yngre (midlere alder 35,7 år, SE $\pm 2,3$ ) enn de i magnesiumfabrikken (midlere alder 48,4, SE $\pm 2,1$ år). En oversikt over midlere alder og midlere verdier av ulike variable laget på grunnlag av spørreskjemaet for de ulike døgnrytme-typer (A, I og B) er gitt i tabell 3 .

Tabell 2. Gammakoeffisient for assosiasjonen mellom ulike faktorer brukt i analysen.

\begin{tabular}{lrrrc}
\hline & 1 & 2 & 3 & 4 \\
\hline 1. Alder & & & & \\
2. Antall år i skift & 0,834 & & & \\
3. Arbeidssted & $-0,826$ & $-0,744$ & & \\
4. A- og B-type & 0,109 & 0,022 & $-0,028$ & \\
5. Lett for å sove & $-0,119$ & $-0,191$ & 0,125 & $-0,339$ \\
\hline
\end{tabular}

Tabell 3. Midlere alder og midlere selvrapporterte mål samt standard feil gitt ved døgnrytmetype (A-, B- og Intermediær (I) type).

\begin{tabular}{lrrc}
\hline & A-type & I-type & B-type \\
Variabel & $\mathrm{N}=5$ & $\mathrm{~N}=9$ & $\mathrm{~N}=5$ \\
\hline Alder & $41,4(6,2)$ & $43,6(3,0)$ & $39,2(3,7)$ \\
Antall år i skiftarbeid & $18,3(5,0)$ & $19,6(2,3)$ & $17,8(3,1)$ \\
Lett for å sove & $4,0(1,7)$ & $5,6(0,7)$ & $6,4(0,6)$ \\
aMT6s døgn, $\mu \mathrm{g} / \mathrm{t}$ & $0,55(0,09)$ & $0,86(0,16)$ & $1,04(0,18)$ \\
aMT6s natt, $\mu \mathrm{g} / \mathrm{t}$ & $0,89(0,17)$ & $1,83(0,35)$ & $1,96(0,28)$ \\
aMT6s kveld, $\mu \mathrm{g} / \mathrm{t}$ & $0,21(0,06)$ & $0,29(0,04)$ & $0,18(0,04)$ \\
\hline
\end{tabular}

En analyse av midlere timeutskillelse av aMT6s første døgn med nattskift og ulike variable ved Spearmans rank korrelasjonstest, viste en ikke-signifikant assosiasjon mellom B-type og høy døgnutskillelse ( $p=0,056$, tabell 4). Et scatterplot av assosiasjonen er vist i figur 1. Vi analyserte assosiasjonen på nytt, nå med en tredeling (1-3, 4-6, 7-9) av A- og B-typer (se tabell 1). Vi fikk nå en signifikant korrelasjon $\left(\mathrm{r}_{\mathrm{sp}}=-0,484, \mathrm{p}=\right.$ 0,036). En partiell korrelasjonsanalyse med kontroll for alder og arbeidssted ga fortsatt et "borderline" resultat $(\mathrm{p}=0,056)$. Alder, antall år $\mathrm{i}$ skiftarbeid og evne til å sove på uvanlig tid og sted var ikke korrelert med døgnutskillelsen første skiftdøgn.

En analyse av midlere timeutskillelse av aMT6s kontrollnatt ( 8 timer) hjemme og ulike variable, viste en signifikant korrelasjon med B- type $(p=0,025$, tabell 5). Et scatterplot av assosiasjon er vist i figur 2. En 


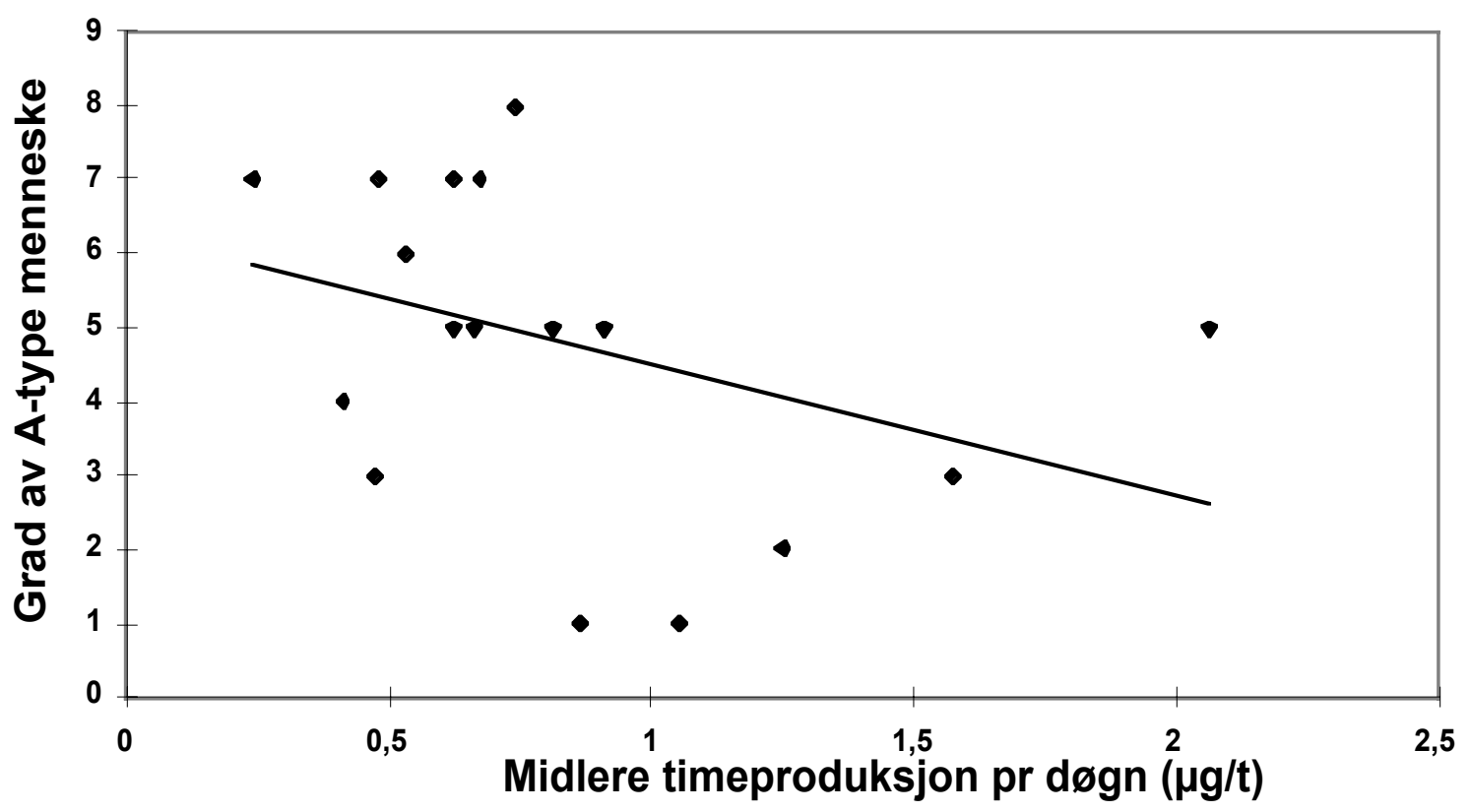

Figur 1. Grad av A-type menneske som funksjon av midlere timeproduksjon av 6-sulfatoksymelatonin pr. døgn hos 19 norske skiftarbeidere første døgn med nattskift.

analyse med en tredeling (1-3, 4-6, 7-9) av A- og Btyper viste også en signifikant assosiasjon $\left(\mathrm{r}_{\mathrm{sp}}=-0,649\right.$, $\mathrm{p}=0,003)$. En partiell korrelasjonsanalyse med kontroll for alder og arbeidssted ga et fortsatt signifikant resultat $(p=0,05)$. Det samme gjorde kontroll for tid i skiftarbeid. De andre parametrene som ble analysert viste ingen korrelasjon med nattutskillelsen hjemme.

Midlere timeutskillelse av aMT6 på kvelden i hjemmedøgnet (4 timer) viste ingen korrelasjon med de variable som inngikk $\mathrm{i}$ analysen (tabeller ikke vist).

\section{DISKUSJON}

Denne studien viser at egenrapporterte B-typer har en tendens til høyere timeutskillelse av aMT6s første døgn på nattskift og en signifikant høyere nattutskillelse (8 timer) hjemme.

Et problem er at vårt materiale er lite og selektert, $\mathrm{i}$ det vi har sett på en gruppe skiftarbeidere, til dels med lang fartstid i skiftarbeid. Dette kan ha gitt gode muligheter for å utvikle en tilpasning av døgnrytmen til denne type arbeid. Det kan også være et innslag av "healthy worker effekt" i populasjonen, med et frafall i jobben for de som har problemer med å arbeide nattskift. Videre er aldersfordelingen i materialet spesiell, i det ansatte i magnesiumfabrikken har et høyere innslag av eldre arbeidstakere enn fullgjødsel III. Arbeidstakerne inkludert i denne studien representerer således ikke normalbefolkning og resultatene kan ikke generaliseres.

Et annet problem i studien er avstanden i tid mellom urinanalysene og innhenting av spørreskjemaet.
Urinprøvene ble samlet inn midtvinters og spørreskjemaet på våren. Vi vet at melatoninsekresjonen fremviser sesongvariasjon, men vi antar at forholdet mellom aMT6s-nivåene er konstant for de respektive døgnrytme-typer (A, I og B).

Tabell 4. Korrelasjon mellom målte verdier av døgnprodusert (24 timer) 6-sulfatoksymelatonin i urin første døgn med nattskift og ulike variable gitt ved Spearmans rank korrelasjonstest.

\begin{tabular}{lccc}
\hline Variabel & antall & Korrelasjon & p-verdi \\
\hline Alder & 19 & 0,175 & 0,414 \\
Antall år i skiftarbeid & 19 & 0,358 & 0,132 \\
Lett for å sove & 19 & 0,045 & 0,855 \\
A- og B-menneske & 19 & $-0,445$ & 0,056 \\
\hline
\end{tabular}

Tabell 5. Korrelasjon mellom målte verdier av nattprodusert (8 timer) 6-sulfatoksymelatonin i urin fra kontrolldøgn og ulike variable gitt ved Spearmans rank korrelasjonstest.

\begin{tabular}{lcc}
\hline Variabel & Korrelasjon & p-verdi \\
\hline Alder & 0,138 & 0,531 \\
Antall år i skiftarbeid & 0,327 & 0,172 \\
Lett for å sove & $-0,068$ & 0,782 \\
A- og B-menneske & $-0,513$ & 0,025 \\
\hline
\end{tabular}




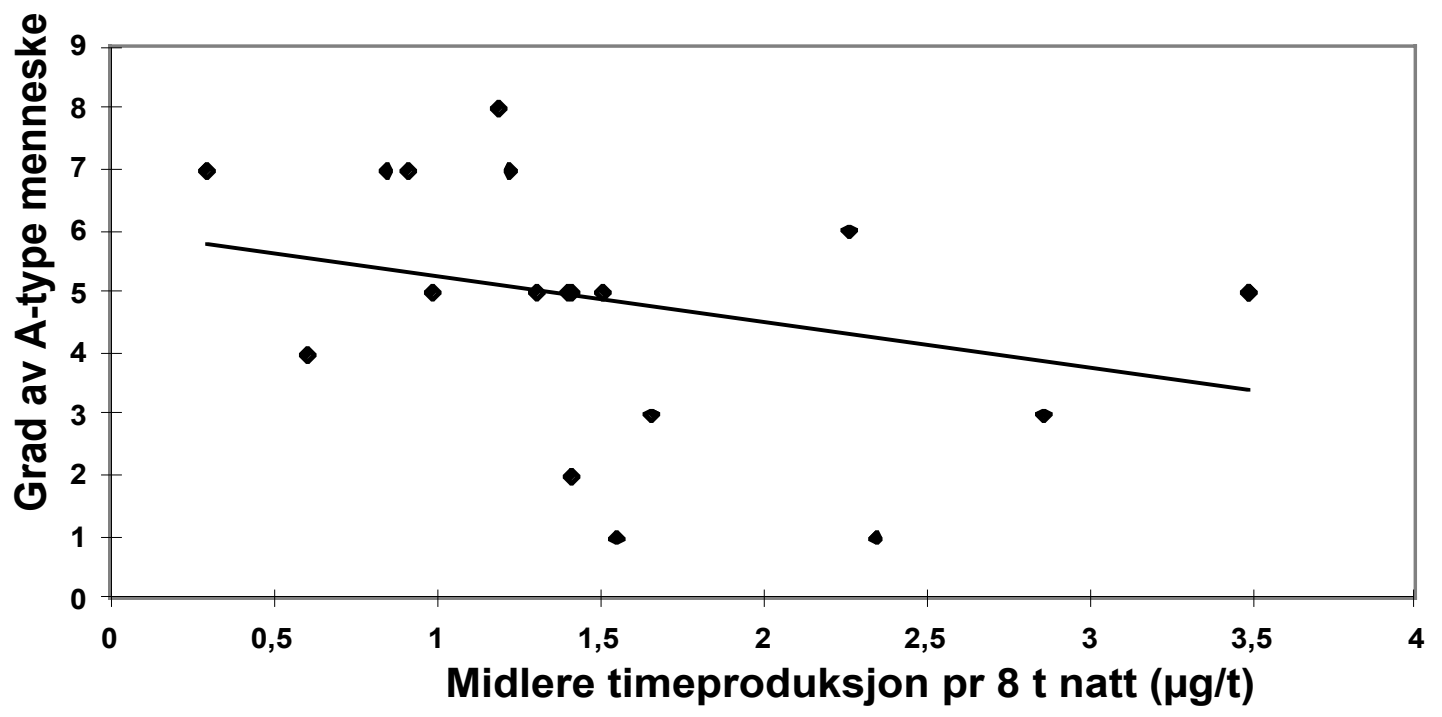

Figur 2. Grad av A-type menneske som funksjon av midlere timeproduksjon av 6-sulfatoksymelatonin, hos 19 norske skiftarbeidere, kontrollnatt hjemme.

En høyere døgnutskillelse av aMT6s hos B-typer som vist når vi brukte den tredelte skalaen for døgnrytmetype, er så vidt vi kjenner til ikke tidligere rapportert $\mathrm{i}$ litteraturen. Også her skal man være forsiktig med å trekke for langtrekkende slutninger. Når det gjelder Aog B-typer og aMT6 ville det kanskje ha vært bedre å evaluere et mønster i døgnutskillelsen heller enn et nivå. Vi hadde ikke data tilgjengelige for å vurdere evt. toppnivået av aMT6 på natten. Vi analyserte nattprodusert mengde som fraksjon av total døgnmengde, men her fant vi ingen signifikant korrelasjon.

En høyere nattutskillelse av aMT6s blant B-typer er ikke i samsvar med funnet til Lacoste og Wetterberg. Studiene er likevel ikke direkte sammenlignbare, da substansen som ble målt i deres studie var urinmelatonin (10). Viktige potensielle confoundere som arbeidssted, tid i skiftarbeid og alder ser ikke ut til å påvirke vårt resultatet $\mathrm{i}$ særlig grad, selv med de nevnte forskjeller i alder og aMT6s-utskillelse ved de to arbeidsplasser. En viktig forskjell mellom vårt materiale og den over nevnte studien, er en høyere gjennomsnittsalder hos våre deltagere.

Normalt vil melatoninsekresjonen målt i blod vise stigning kl. 2100-2200. Denne økningen vil i hovedsak gjenspeiles i aMT6s-nivået i nattprodusert urin. I vår analyse av midlere timeproduksjon på kveld fant vi ingen signifikant effekt $\mathrm{i}$ forhold til døgnrytme-typen. Morgenutskillelsen av aMT6s i hjemmedøgnet har vi ikke sett på i analysen fordi en del av prøvene ikke er tatt ut $\mathrm{i}$ henhold til planlagt protokoll.

En sammenheng mellom A-typer og stigende alder er rapportert ved flere anledninger tidligere $(7,14,15)$. I likhet med Lacoste \& Wetterberg fant ikke vi en slik sammenheng. Siden vårt materiale er lite og siden det $\mathrm{i}$ litteraturen er vist at man utvikler seg i retning av Atyper ved stigende alder, bør man i studier av skiftarbeidere spørre om døgnrytmetype i yngre år, f.eks. ved 20 års alder. Det ble ikke funnet utpregede A- eller B-typer blant de over 50 eller blant de under 30 år.

Denne studien viser at det i videre studier av melatoninsekresjon og utskillelse av metabolitt i urinen, er av stor interesse å samtidig samle inn spørreskjemabaserte opplysninger om døgnrytmetype og utfyllende opplysninger om søvn og søvnmønster i relasjon til eksponeringer som skiftarbeid og eksponering for andre arbeidsmiljøfaktorer med potensiell hormonell effekt i skiftarbeid.

\section{REFERANSER}

1. Brzezinski A. Melatonin in humans. N Engl J Med 1997; 336: 186-95.

2. Lerner AB, Case JD, Takahashi Y, Lee TH, Mori W. Isolation of melatonin, the pineal gland factor that lightens melanocytes. J Am Chem Soc 1958; 80: 2587.

3. Haimov I, Laudon M, Zisapel N, Souroujon M, Nof D, Shlitner A, Herer P, Tzischinsky O, Lavie P. Sleep disorders and melatonin rhythms in elderly people. BMJ 1994; 309: 167. 
4. Lewy AJ, Sack RL, Blood ML, Bauer VK, Cutler NL, Thomas KH. Melatonin marks circadian phase position and resets the endogenous circadian pacemaker in humans. Ciba Found Symp 1995; 183: 303-17.

5. Kleitman N. Sleep and wakefulness. Chicago: University of Chicago Press, 1963.

6. Fröberg JE. Twenty-four hour patterns in human performance, subjective and physiological variables and differences between morning and evening active subjects. Biol Psychol 1977; 5: 119-34.

7. Horn JA, Østberg O. A self-assessment questionnaire to determine morningness-eveningness in human circadian rhytms. Int J Chronobiol 1976; 4: 97-110.

8. Monk TH, Reynolds CF, Buysse DJ, Hoch CC, Jarrett DB, Jennings JR, Kupfer DJ. Circadian characteristics of healthy 80-year-olds and their relationship to objectively recorded sleep. J Gerontol 1991; 46: M171-5.

9. Kerkhof GA. Inter-individual differences in the human circadian system: a review. Biol Psychol 1985; 20: 83112.

10. Lacoste V, Wetterberg L. Individual variations of rhythms in morning and evening types with special emphasis on seasonal differences. I: Wetterberg L (red.) Light and biological rhytms in man. Oxford: Pergamon Press, 1993: 287-304.

11. Folkard S, Barton J, Spelten E, Totterdell P, Smith L, Costa G. The Standard Shift Worker Index: A battery of questionnaires for assessing shiftwork-related problems. Work Stress 1995; 9: 4-30.

12. Haugsdal B. Biorytmeforstyrrelser i arbeidslivet. StrålevernRapport 1998:12. Østerås: Statens strålevern.

13. SPSS Base 7.5 Syntax Reference Guide. Chicago, IL: SPSS Inc, 1995.

14. Maccaci L, Zani A, Rochetti G, Lucioli R. The relationship between morningness-eveningness, aging and personality. Person Indiv Diff 1986; 7: 911-3.

15. Webb WB, Bonnet MH. The sleep of the "morning" and "evening" types. Biol Psychol 1978; 7: 29-35. 